\title{
Investigating Soot Parameters in an Ethane/air Counterflow Diffusion Flame at Elevated Pressures
}

\author{
Hafiz M. F. Amin* and William L. Roberts \\ Clean Combustion Research Center \\ King Abdullah University of Science and Technology (KAUST) \\ Thuwal, 23955-6900, Saudi Arabia
}

* Corresponding author:

Hafiz M. F. Amin

Clean Combustion Research Center

King Abdullah University of Science and Technology (KAUST)

Thuwal, 23955-6900, Saudi Arabia

Email: hafiz.amin@kaust.edu.sa

Phone: +447568966134 


\title{
Investigating Soot Parameters in an Ethane/air Counterflow Diffusion Flame at Elevated Pressures
}

\begin{abstract}
Soot emissions from diesel engines and gas turbines are influenced by the combustion environment. Pressure is one of the parameters which affects particulate emissions and these effects are poorly understood on soot parameters. In this work, pressurized counterflow diffusion flame of ethane and air has been investigated using two angle light scattering and extinction technique. A counterflow diffusion flame has been stabilized from 2 to $5 \mathrm{~atm}$ in a pressure vessel which can provide optical access from 10 to $165^{\circ}$ in angular direction. Global strain rate $(a)$ of 30 $s^{-1}$ is maintained at all pressures by adjusting the inlet flows. Scattering measurements are performed at two angles $\left(45^{\circ}\right.$ and $\left.135^{\circ}\right)$ and Rayleigh-Debye-Gans theory for Fractal Aggregates (RDG-FA) has been used to determine soot parameters from light scattering and extinction data. By combining the scattering at $135^{\circ}$ with laser extinction measurements, path averaged soot volume fraction $\left(f_{\mathrm{v}}\right)$, mean primary particle diameter $\left(\overline{d_{p}}\right)$ and particle number densities $\left(n_{\mathrm{p}}\right)$, along the axis of the counterflow flame are calculated. Local soot volume fraction $\left(f_{\mathrm{v}, \text { local }}\right)$ profiles are also measured using diffuse light 2D line of sight attenuation technique. Peak value of $f_{\mathrm{v}}$ increases from $0.3 \mathrm{ppm}$ to $8 \mathrm{ppm}$ as the pressure is raised from 2 to $5 \mathrm{~atm}$. Primary particle size $\left(\overline{d_{p}}\right)$ also increases with pressure where peak primary particle size of $11 \mathrm{~nm}$ at 2 atm rises to $38 \mathrm{~nm}$ at 5 atm. Population average radius of gyration $\left(R_{\mathrm{g}}\right)$ increases with pressure while the number densities $\left(n_{\mathrm{p}}\right)$ of primary particles decrease due to coalescence.
\end{abstract}

Keywords: light scattering, soot, counterflow, laminar flame, primary particle size 


\section{Introduction}

High operating pressure is desirable in gas turbines and diesel engines in order to reduce the volume of combustion chamber and to improve thermodynamic efficiency of the combustion devices. Soot formation is appreciably enhanced with pressure. Soot emissions from the exhaust of combustion systems pose serious risk to human health (Kennedy, 2007) and they are also a major contributor to global warming (Ramanathan and Carmichael, 2008). Morphology of these combustion generated particles affects their transport properties and their interaction with human respiratory system (Broday and Rosenzweig, 2011). Furthermore, air-borne life time of these particles is determined by their morphological parameters (Pope III and Dockery, 2006). Therefore, it is necessary to understand the morphology of soot at conditions relevant to practical combustion systems in order to improve computational codes to predict soot in real combustion environment and to develop effective emission control strategies.

Both intrusive and non-intrusive diagnostics have been used for many years in laboratory flames at atmospheric pressure to study soot (Sorensen et al., 1992, Koylu, 1997, Hu et al., 2003, Fang et al., 1998, De Iuliis et al., 1998a, De Iuliis et al., 2011, Cortés et al., 2018, Ferraro et al., 2016). Laser diagnostics are favored for soot studies in flames due to their non-perturbing nature. However, necessity of optical access for using laser diagnostic at elevated pressure makes the experimental setup very complex and the diagnostic itself becomes quite challenging. Therefore, this area of research has not been given much attention and limited studies are available at elevated pressures in which effects of pressure on soot volume fraction and particle size have been studied (Hofmann et al., 2003, Thomson et al., 2005, Bennett et al., 2018, Joo et al., 2018). Bennett et al. (2018) reported soot concentration profiles in coflow flames to a pressure of 16 bar. Diffuse light 2D line of sight attenuation (diffuse 2D-LOSA) and laser induced incandescence (LII) were used 
for investigating the influence of pressure on soot volume fraction. Soot concentration increased with pressure and polycyclic aromatic hydrocarbons (PAH) absorption had limited effects on LOSA measurements while the uncertainties due to scattering to absorption ratio $\left(\rho_{\text {sa }}\right)$ increased with pressure due to change in morphology of soot. Thomson et al. (2006) studied the effects of pressure on effective particle diameter of soot in methane/air coflow flames up to a pressure of 4.0 Mpa. They used laser induced incandescence technique to measure particle size and found a dramatic increase in particle size with pressure. Effective particle size does not represent the mean primary particle diameter $\left(\overline{d_{p}}\right)$ which can be investigated by using thermophoretic sampling followed by transmission electron microscopy (TS-TEM) or light scattering and absorption measurements. Vargas and Gülder (2016) measured primary particle size using TS-TEM in methane air coflow flames to a pressure of $10 \mathrm{~atm}$. They reported an overall decrease in primary particle size with pressure. Joo et al. (2018), performed TS-TEM in ethylene air coflow flames to a pressure of 20 bar and they found that the primary particle size increased by increasing the pressure up to 15 bar. Increasing the pressure to 20 bar resulted in a small increase or the primary particle size is found to decrease. Most of the high pressure flames focused on soot studies are coflow flames in which high pressure of $10 \mathrm{MPa}$ have been reached (Joo and Gülder, 2010). However, coflow flames exhibit some problems at elevated pressures, such as heat loss to the burner rim which is difficult to account (Joo and Gülder, 2010). Moreover, they have twodimensional structure and thus complex flow pattern which make soot formation/oxidations mechanisms difficult to understand.

Sooting flames have also been studied in opposed flow configuration at elevated pressures (Amin and Roberts, 2017, Xue et al., 2018, Amin and Roberts, 2019). Counterflow flames are relatively immune from buoyancy induced instabilities and this configuration allows to control the residence 
time by controlling the strain rates. Amin and Roberts (2017) measured population averaged radius of gyration $\left(R_{g}\right)$ and $\overline{d_{p}}$ using two angle light scattering and extinction techniques. They found that both $R_{g}$ and $\overline{d_{p}}$ increased with increasing the pressure. In a recent study by Amin et al. (2019), $\overline{d_{p}}$ was also investigated using TS-TEM in ethylene/air counterflow flames up to $10 \mathrm{~atm}$. The study reported increase in $\overline{d_{p}}$. Size distribution of primary particles were averaged over the entire soot zones. Due to the small thickness of soot zones in counterflow flames, it was not possible to resolve the measurements along the flame axis. Most of the high-pressure studies discussed above have been reported in methane/air or ethylene/air flames. Ethane is not a commonly used fuel for combustion applications. However, it is produced in abundance due to the pyrolysis of large hydrocarbons based practical fuels during combustion applications (Mandatori and Gülder, 2011, Mei et al., 2018). Therefore, investigating influence of pressure on intermediate molecules like ethane is of practical relevance and offers the advantage of reduced experimental complexities. Furthermore, gas phase chemistry of these gaseous fuels is well understood.

In this work, we have used two angle light scattering and extinction technique to investigate the effects of pressure on soot parameters. Two angle light scattering and extinction have been used by many researchers to retrieve soot parameters in diffusion flames at atmospheric pressure (De Iuliis et al., 1998a, De Iuliis et al., 1998b, Yang and Koylu, 2005, Bo Yang and U. O. Koylu, 2005). An ethane/air counterflow diffusion flame has been stabilized from 2 to 5 atm in a pressure vessel which can provide the required optical access for laser diagnostics. Measurements of the scattering signals at $45^{\circ}$ and $135^{\circ}$ in conjunction with light extinction data enable retrieving mean radius of gyration, primary particle diameter and soot volume fraction along the axis of counterflow flame at elevated pressures. Local soot volume fraction profiles at elevated pressures 
are also inferred by Abel deconvolution of radial transmission data of diffuse 2D-LOSA measurements.

\section{Experimental setup}

A schematic of experimental setup is shown in Figure 1 and the setup for laser light scattering and extinction has been described in (Amin and Roberts, 2017). Only a brief description is given here for reader's convenience. Experimental setup consists of a pressure vessel in which a counterflow flame is stabilized in pressurized environment. Vessel has four quartz windows of curved shape which can provide optical access up to $165^{\circ}$ in angular direction. A blind flange closes the vessel and can be raised or lowered using a motorized mechanism. Fuel, air and inert supplies inside the pressure vessel are provided through the connectors attached to a blind flange. An exhaust line from the top of the vessel is connected to an electronically controlled back pressure regulator. A rotary stage is resting on four vertical translation stages attached to the vessel and these translation stages allow to balance the rotary stage in horizontal plane. Scattered light collection optics are mounted on the rotary stage which enables us to position the optics at desired angles.

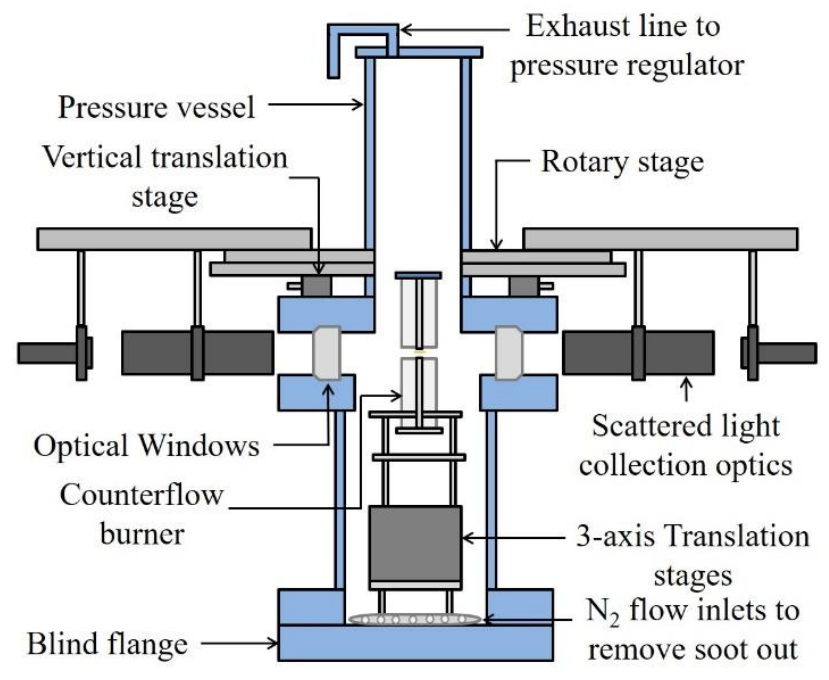

Figure 1. Schematic of setup 
Two counterflow burners have been used for this study. The counterflow burner used

for two angle light scattering and extinction measurements has two opposed straight tubes of inside diameter of $8.1 \mathrm{~mm}$. A separation distance $(H)$ of $8.1 \mathrm{~mm}$ between the fuel and oxidizer tubes is kept constant. For diffuse light 2D line of sight attenuation measurements, inside diameter of the fuel and oxidizer tube is increased to $8.5 \mathrm{~mm}$ and $H$ between the tubes is maintained as $\mathbf{8 ~ m m}$. Air is provided from the top side while the ethane is supplied from the bottom side of the burner. Global strain rate $(a)$ is defined as the average velocity of air $\left(V_{\text {air }}\right)$ at the exit of the nozzle divided by half of the separation distance $(H)$ between the nozzles (C. J. Sung et al., 1998) and $a=30 \mathrm{~s}^{-1}$ is maintained at all pressures while fuel and oxidizer streams have equal momentum. Fuel mole fraction is $X_{\mathrm{f}}=1.0$. Flame with pure fuel/air combustion studied is soot formation flame, located on the oxidizer side of the stagnation plane (Wang and Chung, 2019). To prevent entrainment, a nitrogen curtain with a matching velocity of core jets is provided through coflow tubes of inside diameter of $28 \mathrm{~mm}$. The burner is mounted on xy-translation stages which allow to align the center of the burner with the laser beam. An xy-translation stages and the burner are attached on a vertical translation stage which has minimum resolution of $0.005 \mathrm{~mm}$ and allows vertical displacement of $25 \mathrm{~mm}$ in z-direction. To prevent the accumulation of soot on the optical windows a flux of nitrogen gas flows around the optical windows without perturbing the flame and this nitrogen flow is provided through a circular ring attached on the blind flange.

Figure 2 shows the schematic of optical arrangement for light scattering, extinction and diffuse 2D-LOSA diagnostics. A vertically polarized laser beam, at a wavelength of $514.5 \mathrm{~nm}$, is emitted by an $\mathrm{Ar} / \mathrm{Kr}$ ion laser light source and is chopped at $1 \mathrm{kHz}$. The sending optics expand the laser beam which is then focused to a beam waist diameter of $0.1 \mathrm{~mm}$ at the center of the burner. The scattered light collection optics consist of a converging lens which collects the scattered light 
by the soot particles and focuses it to a pinhole of $0.15 \mathrm{~mm}$ diameter. A polarizer is mounted before a pinhole which allows the measurement of vertically polarized light only. Unwanted light from the surrounding and flame radiations are minimized by using a lock-in-amplifier and a bandpass filter in front of PMT.

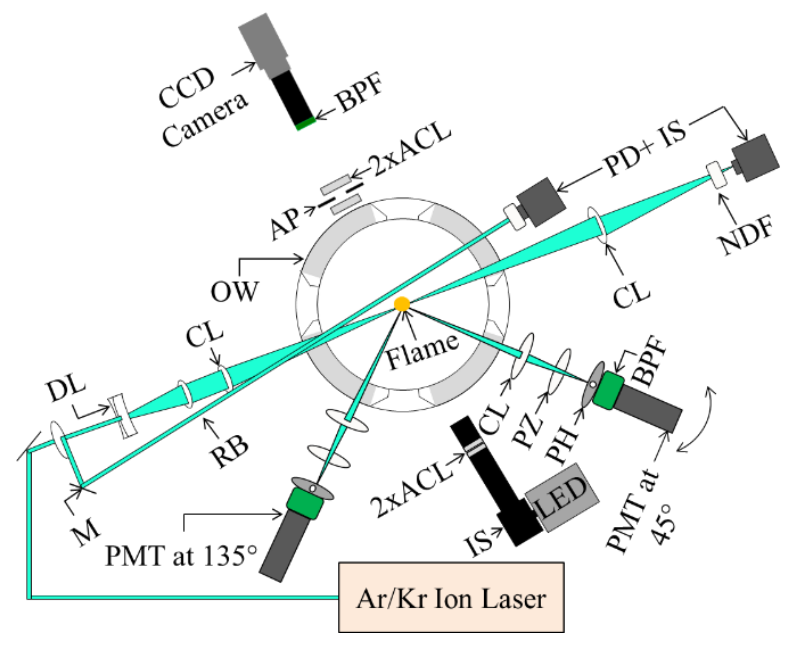

Figure 2. Schematic of optical diagnostics: $M=$ Mirror; $D L=$ Diverging lens; $R B=$ Reference beam; $\mathrm{CL}=$ Converging lens; $\mathrm{PZ}=$ Polarizer; $\mathrm{PH}=$ Pinhole; $\mathrm{BPF}=$ Bandpass filter; $\mathrm{PMT}=$ Photomultiplier tube; $\mathrm{PD}=$ Photodiode; IS = Integrating sphere; NDF = Neutral density filter; OW $=$ Optical window; $\mathrm{ACL}=$ Achromatic converging lens; $\mathrm{AP}=$ Aperture

Scattering intensity by soot particles, $I_{v v}{ }^{\text {soot }}$, is measured at particular location and the soot scattering coefficient, $K_{v v}{ }^{\text {soot }}$, at each location is calculated using the following

$$
K_{v v}^{\text {soot }}=K_{v v}^{\text {calib }} \frac{I_{v v}^{\text {soot }}}{I_{v v}^{\text {calib }}}
$$

Where, $I_{v v}{ }^{c a l i b}$, is the scattering intensity and $K_{v v}{ }^{c a l i b}$ is the known scattering coefficient of the calibration gas. Propane is used as the calibration gas. Scattering signal from the nitrogen gas is also measured and the noise from the internal reflections is calculated through the known ratio of the scattering coefficients of propane and nitrogen. Neutral density filters are used during the measurements of the scattering signal from soot particles due to several order of magnitude 
differences in the scattering intensities between the soot particles and the calibration gases. To ensure that the laser power reaching to the measurement volume in the flame is same as that of the calibration gases, correction of the incident and scattering light intensities is required. It is done by considering the attenuation of the laser signal from flame edge to the measurement location and from measurement location to the detector.

Laser light extinction is measured using a photodiode attached on an integrating sphere. Transmitted laser beam, $I$, is focused on the integrating sphere using a biconvex lens. Integrating sphere is used to minimize the effects of beam steering. The incident, $I_{o}$, and the transmitted light intensities, $I$, are measured without and with the flame, respectively. A reference laser beam is also passed through the pressure vessel and the reference beam signal is measured to account for any change in laser power and optical transmissivity of optical windows due to soot accumulation, over time. Extinction coefficient of soot is related to the ratio of the incident $\left(I_{o}\right)$ and transmitted (I) light intensities as follows

$$
\left(K_{\text {ext }}=-\frac{1}{\Delta s} \ln \frac{I}{I_{o}}\right)
$$

For laser light extinction measurement $\Delta \mathrm{s}$ is the absorption path length and is obtained from the images of soot zone by using intensity threshold algorithm.

To perform diffuse 2D-LOSA, two LED light sources are attached to a 2-inch integrating sphere. Output of the integrating sphere is white light having Lambertian distribution. A diffused light exited through a $12 \mathrm{~mm}$ port of the integrating sphere is imaged on the center plane of the burner using a combination of achromatic lenses of $300 \mathrm{~mm}$ and $100 \mathrm{~mm}$ focal length. This combination of the lenses gives a magnification of 3 that illuminates the entire flame. The center plane of the burner is imaged onto a CCD camera (PIXIS 400F CCD) using a combination of two achromatic lenses, each having $750 \mathrm{~mm}$ focal length and diameter of $50 \mathrm{~mm}$. To increase the $f$ - 
number of the light collection lenses, an aperture of $12.5 \mathrm{~mm}$ diameter is placed in between the lenses. A band pass filter of $514.5 \pm 1 \mathrm{~nm}$ is mounted on the camera and its dynamic range is optimized by choosing appropriate exposure time and gain.

From diffuse 2D-LOSA, transmissivity $\tau$ is measured using the following relation

$$
\tau=\frac{I}{I_{o}}=\frac{\text { FlameLamp-Flame }}{\text { Lamp-Dark }}
$$

Where the 'FlameLamp' is the signal when both flame and lamp are on. The 'Flame' represents the signal when only the flame is on and the lamp is turned off; 'Lamp' is the signal when no flame is on and 'Dark' is the signal when neither flame nor the lamp is on. By taking three-point Abel inversion (Dasch, 1992) of line-of-sight transmission data, local $K_{\text {ext }}$ is calculated using BeerLambert law (Thomson et al., 2008).

\section{Theoretical Methods}

Soot parameters are calculated following the detailed analysis of (Koylu, 1997) based on the Rayleigh-Debye-Gans theory for fractal aggregates of small spherical particles. Soot volume fraction can be calculated from the extinction measurements as

$$
f_{v}=\frac{\lambda}{6 \pi E} \frac{K_{e x t}}{\left(1+\rho_{s a}\right)}
$$

Here, $\lambda$ is the wavelength used, $\mathrm{E}=\operatorname{Im}\left[\left(m^{2}-1\right) /\left(m^{2}+2\right)\right], m$ is the complex refractive index of soot and $\rho_{\mathrm{sa}}$ is the scattering to absorption ratio. The variation in the value of complex refractive index of soot is not known as a function of pressure and $m=1.62+0.66 i$ reported by (Krishnan et al., 2000) is chosen at all pressures. This value is reported for the same wavelength used in this experimental study and is shown to be independent of fuel type within the experimental uncertainties. The value of $E$, with experimental uncertainties corresponding to the chosen value of complex refractive index is $0.29 \pm 27 \%$ (Krishnan et al., 2000). The ratio of the total scattering to extinction ratio is not constant and depends on the flame conditions as it changes with the 
particle diameter and aggregate size. Considering the results of (Migliorini et al., 2011), at atmospheric pressure, in which $\rho_{\mathrm{sa}}$ is found to change between 0.036 to 0.11 for the wavelength used in the present study, the value of $\rho_{\mathrm{sa}}$ is assumed to be 0.1 for all the flame conditions with $100 \%$ uncertainty as its contribution can be negligible at locations near the flame (Amin and Roberts, 2019). The choice of scattering measurement at $45^{\circ}$ and $135^{\circ}$ enables to improve the signal to noise ratio of the signal from calibration gases and these angles are considered to correspond to the Guinier and Power-law regime, respectively. Particle diameter is calculated from the scattering to absorption ratio at $135^{\circ}$ using the following relation

$$
d_{p}=\frac{\lambda}{\pi}\left[4 \pi \frac{E}{F} \frac{K_{v v}\left(\theta_{L}\right)}{K_{a b s}} \frac{\left(2 \sin \theta_{L} / 2\right)^{D_{f}}}{k_{f}}\right]^{1 /\left(3-D_{f}\right)}
$$

Here, $K_{a b s}$ is the absorption coefficient and is equal to $K_{\text {ext }}$ times $\left(1+\rho_{\text {sa }}\right)^{-1} \cdot F(m)=\mid\left(m^{2}-1\right) /\left(m^{2}+\right.$ 2) $\left.\right|^{2}, k_{f}$ is the fractal prefactor and $D_{f}$ is the fractal dimension. The value of $F$ with the reported uncertainties for the chosen value of complex refractive index is $0.27 \pm 44 \%$ (Krishnan et al., 2000). $\boldsymbol{D}_{\boldsymbol{f}}=\mathbf{1 . 8}$ and $\boldsymbol{k}_{\boldsymbol{f}}=\mathbf{2 . 0}$ are employed for the present analysis as these values are shown to be representing the morphology of flame generated aggregates in a wide range of combustion conditions (Koylu et al., 1995). Once the soot volume fraction and primary particle size are known, particle number density is calculated using $n_{p}=\left(6 \times f_{v}\right) /\left(\pi \times d_{p}{ }^{3}\right)$. According to RDG-FA theory, fractal dimension, $D_{\mathrm{f}}$, and fractal prefactor, $\boldsymbol{k}_{\mathrm{f}}$, relate the number of primary particles in an aggregate, $N$, to its radius of gyration, $R_{g}$, by the relation

$$
N=K_{f}\left(\frac{2 R_{g}}{d_{p}}\right)^{D_{f}}
$$

Mean aggregate radius of gyration is calculated from the measurement of dissymmetry ratio $R_{v v}$

$$
R_{v v}\left(\theta_{1}\right)=\frac{K_{v v}\left(\theta_{1}\right)}{K_{v v}\left(\theta_{2}\right)}=\frac{\int N^{2} S\left(q_{1} R_{g}\right) p(N) d N}{\int N^{2} S\left(q_{2} R_{g}\right) p(N) d N}
$$


Where, $S\left(q_{1} R_{g}\right)$ is the aggregate structure factor for which numerous relationships are available, but in the present study, relation proposed by Lin et al. given in (Sorensen, 2001) is employed:

$$
S\left(q R_{g}\right)=\left[1+\sum_{t=1}^{4} C_{t}\left(q R_{g}\right)^{2 s}\right]^{-D_{f} / 8}
$$

Here, $q=(4 \pi / \lambda \sin \theta / 2)$ is the scattering wave vector and $C_{1}=8 /\left(3 D_{f}\right), C_{2}=2.5, C_{3}=-1.52, C_{4}=$ 1.02. In order to account for the polydispersity of fractal aggregates a log normal size distribution with a geometric width $\sigma_{\mathrm{g}}=2.1$ is assumed considering the results of (Amin et al., 2019) in this pressure range. Equation (7) along with Equations (6) and (8) are solved numerically for the mean radius of gyration, $R_{g}$.

\section{Results}

Path averaged soot volume fraction $\left(f_{\mathrm{v}}\right)$ and local soot volume fraction $\left(f_{\mathrm{v}, \text { local }}\right)$ profiles measured along the axis of the counterflow flame from 2 to $5 \mathrm{~atm}$ are shown in Figure 3(a) and Figure 3(b), respectively. Peak values of these profiles are shifted to have their peaks aligned at the same location. These profiles are presented as a function of the distance from maximum value which is close to the stagnation plane. The distance from peak value is positive towards the air nozzle while it is negative towards the fuel nozzle. At $1 \mathrm{~atm}$ the soot loading was not enough to allow us to accurately measure $f_{\mathrm{v}}$. Pure ethane/air flame is a soot formation flame and the sooting zones are located on the oxidizer side of the stagnation plane. Flames are located on the air side of stagnation plane. Soot is produced near the flame and $f_{\mathrm{v}}$ increases as soot particles move from the near flame region towards the stagnation plane where they leak out. Soot volume fraction significantly increases with pressure and the maximum values of $f_{\mathrm{v}}$ calculated from laser light extinction data are $0.3,1.3,3.8$ and $7.9 \mathrm{ppm}$ from 2 to $5 \mathrm{~atm}$, respectively. If the peak soot volume fractions $\left(f_{\mathrm{v}}\right)$ are fitted to a power law, they scale with pressure as $P^{3.6}$ which is higher compared 
to what has been reported in coflow flames where $f_{\mathrm{v}, \text { peak }}$ scales globally as $P^{2.2}$ (Steinmetz et al., 2016). In Figure 3a, error bars show the uncertainty contribution due to detector's response, absorption length, $\rho_{\mathrm{sa}}$ and refractive index function, $E(\mathrm{~m})$. Local soot volume fraction profiles are shown in Figure 3(b). Maximum values of local soot volume fractions are 0.25, 1.12, 3.9 and 7.89 at pressures of 2, 3, 4 and 5 atm, respectively and the peak local soot volume fraction is found to scale with pressure as $P^{3.9}$. These flames have been studied at constant strain rate which results in the identical temperature-time histories of particles that are of supreme importance in soot (Figura and Gomez, 2014, Figura et al., 2015).

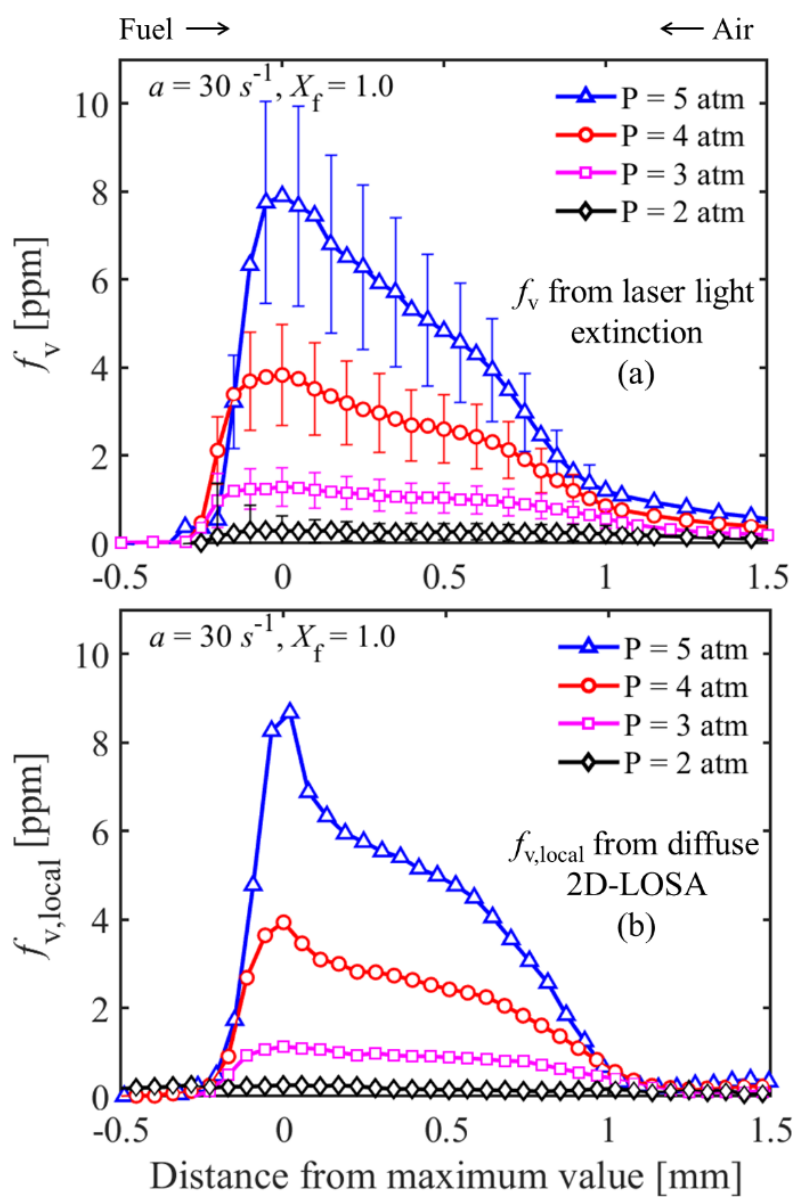

Figure 3. Path averaged (a) and local (b) soot volume fraction profiles along flame axis at elevated pressures 
Radial profiles of $f_{\mathrm{v}, \text { local }}$ obtain from 2D-LOSA at 3 and 5 atm are shown in Figure 4. ' $\mathrm{z}$ ' shows the distance along flame axis and $\mathrm{z}=0$ at peak value of $f_{\mathrm{v}, \text { local. }}$. A higher value of ' $\mathrm{z}$ ' shows the axial location closer to air nozzle. Radial profiles of the flames nearly remain one-dimensional close to the center of the flame. $f_{\mathrm{v}, \text { local }}$ increase as the ' $\mathrm{z}$ ' decreases. Moreover, $f_{\mathrm{v}, \text { local }}$ drops to zero at a varying radial distance at each axial height. The radial distance at which $f_{\mathrm{v}, \text { local }}$ drops to zero decreases along axis, from near flame locations towards peak value of $f_{\mathrm{v}, \text { local }}$, due to the curvature of flame.

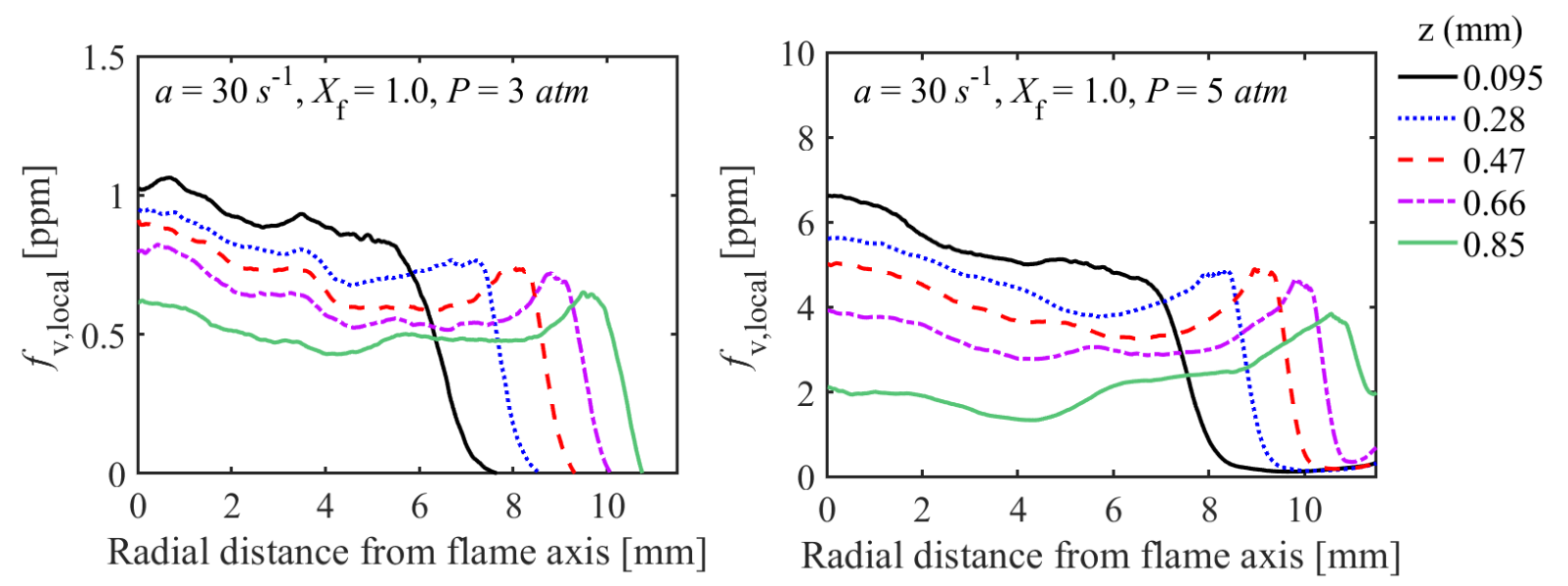

Figure 4. Radial $f_{\mathrm{v}, \text { local }}$ profiles for ethane/air counterflow flames at five different heights. ' $\mathrm{z}$ ' represents the axial distance from peak value of $f_{\mathrm{v}, \text { local }}$ and increases towards flame location. Axial profiles of scattering coefficients measured at $45^{\circ}$ and $135^{\circ}$ along the axis of the flame are shown in Figure 5 (a). On the right side of the maximum value, at each pressure scattering coefficients at both angles start to increase near the flame and in this region scattering coefficients are almost equal showing Rayleigh scattering behavior of small un-aggregated particles. As the particles are transported towards the stagnation plane, the values of scattering coefficients at $45^{\circ}$ becomes higher than scattering coefficients at $135^{\circ}$ due to aggregation processes producing aggregates. The dissymmetry ratios $\left(R_{\mathrm{vv}}\right)$, calculated from the ratio of scattering coefficients $\left(K_{v v}\left(45^{\circ}\right) / K_{v v}\left(135^{\circ}\right)\right)$ at different pressures are shown in Figure 5 (b). $R_{\mathrm{Vv}}$ increases as the soot 
particles move from near flame region towards the stagnation plane and it also shows an increase as the pressure is increased. Variation of dissymmetry ratio is dependent on the structure of the aggregates and an increase in $R_{\mathrm{vv}}$ indicates an increase in population averaged radius of gyration. $R_{v v}$ greater than 1.05 are chosen for calculating the mean aggregate size in order to reduce the experimental uncertainties. At $2 \mathrm{~atm}$, there are not enough values of $R_{v v}$ greater than 1.05 and that is why they are not shown at that pressure.

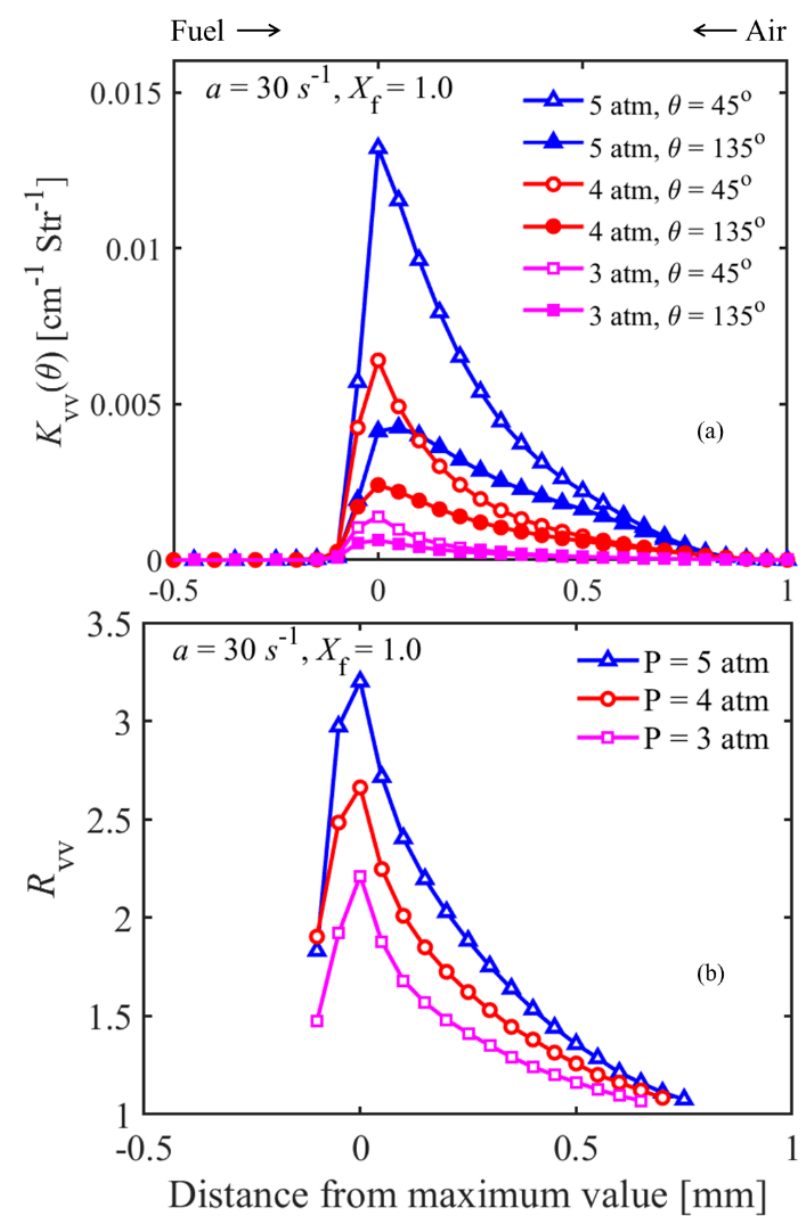

Figure 5. Measured scattering coefficients (a) and calculated dissymmetry ratio (b) along flame axis at elevated pressures

Figure 6 shows the variation of the mean primary particle diameter measured along the axis of the counterflow flame at various pressures. Major sources of uncertainties are absorption 
coefficient, $E(\mathrm{~m}), F(\mathrm{~m})$ and scattering coefficient. Soot particles begin to form near the fuel side of the flame, and they grow as they move along the flow field towards the stagnation plane. No oxidation is present in this soot formation flame. Therefore, particle diameters reach to their maximum values near the stagnation plane where they are convected away. Mean particle diameter also increases with pressure. Peak diameter of $11 \mathrm{~nm}$ at $2 \mathrm{~atm}$ increases to around $38 \mathrm{~nm}$ at $5 \mathrm{~atm}$. From $4 \mathrm{~atm}$ to $5 \mathrm{~atm} \overline{d_{p}}$ remains nearly unchanged.

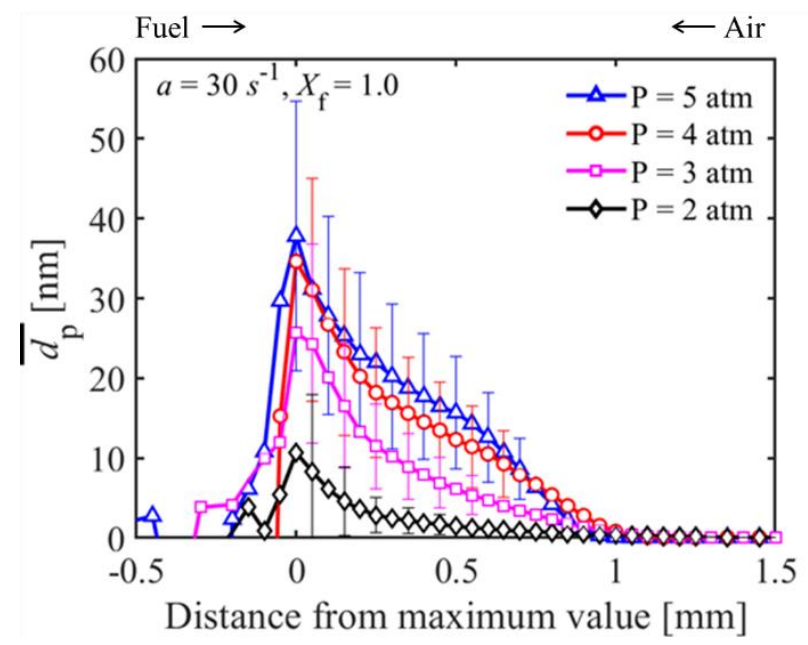

Figure 6. Profiles of primary particle diameter along flame axis at elevated pressures

Number densities of primary particles as a function of the distance from minimum value are shown in Figure 7. At each pressure particle number densities are high near the soot inception zone due to the nucleation process and they start to decrease while moving away from this zone towards the stagnation plane. Particle number densities decrease rapidly in the direction of particle transport but the particle size, as shown in Figure 6, increases as the particles are convected towards stagnation plane. This behavior shows that the number densities decrease in the direction of particle transport due to coalescence. At each axial location along the axis of the flame the number densities of the primary particles decrease due to increased coalescence with pressure. 


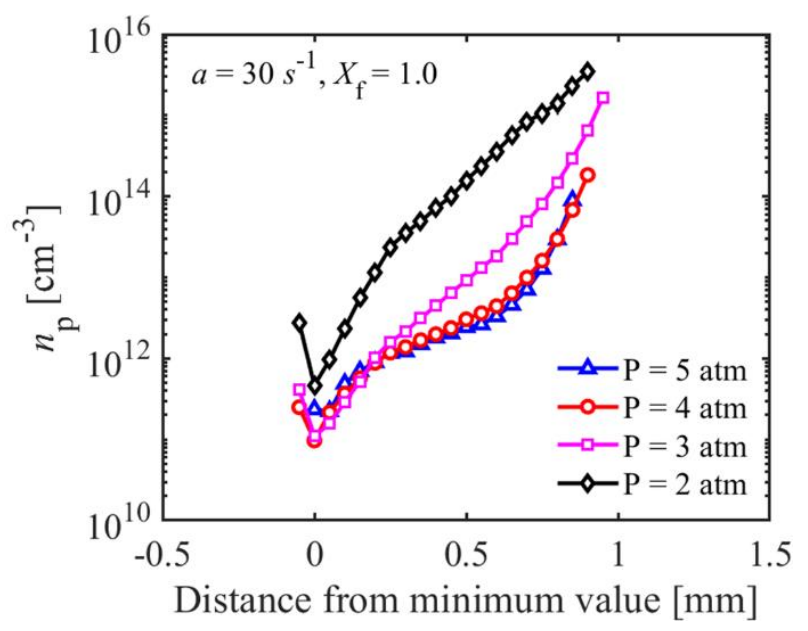

Figure 7. Profiles of number densities of soot particles along flame axis at elevated pressures

Figure 8 shows the profiles of population averaged radius of gyration of aggregates calculated from the dissymmetry ratio. $\sigma_{\mathrm{g}}=2.1$ is assumed for calculating the radius of gyration from dissymmetry ratio whereas $\sigma_{\mathrm{g}}$ is assumed to vary from 1.9 to 2.3 for the uncertainty analysis. Mean aggregate size shows similar trend to that of primary particle diameter and increases as the soot particles move towards the stagnation plane. The increase in $R_{g}$ can be understood by two factors, particle diameter and average number of particles in an aggregate, as mean aggregate size is proportional to $N^{1 / 1.8} d_{p}$ as stated in Equation 6. At each pressure, increase in $R_{g}$ along the axis is due to increase in $\overline{d_{p}}$ which might have accompanied increase in $N . R_{g}$ also increases with pressure and peak aggregate size of approximately $54 \mathrm{~nm}$ at $3 \mathrm{~atm}$ is increased to $78 \mathrm{~nm}$ at $5 \mathrm{~atm}$. 


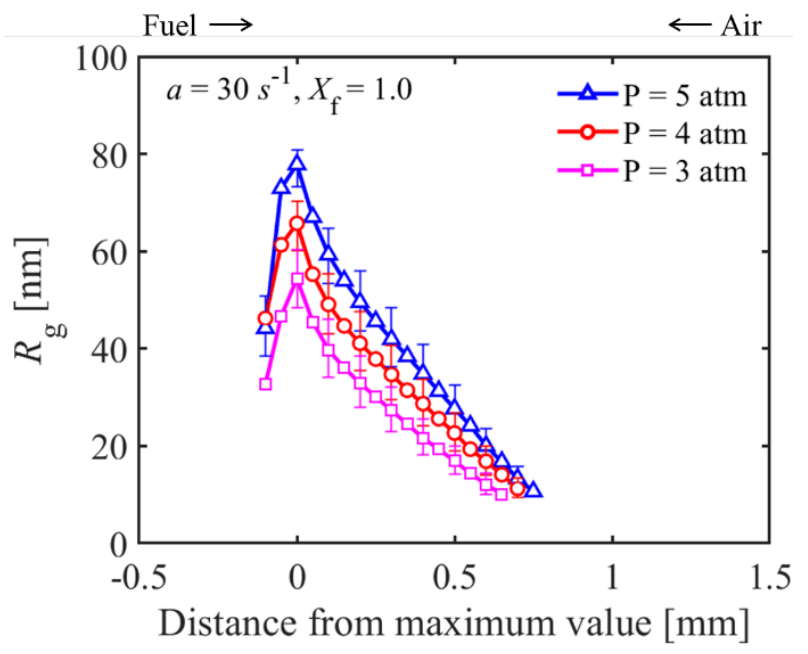

Figure 8. Profiles of mean radius of gyration of soot aggregates along flame axis at elevated

pressures

\section{Conclusions}

Effects of pressure on soot parameters are studied in an ethane/air counterflow diffusion flame. Ethane has less sooting tendency than ethylene. From the light scattering and extinction measurements mean particle diameter, soot volume fraction, aggregate size and particle number densities are calculated, using RDG theory for fractal aggregates.

Integrated soot volume fraction increases with pressure and path averaged peak soot volume fraction scales with pressure according to power law, where the exponent of pressure is 3.62. The pressure exponent for these flames is close to what has been reported for ethylene counterflow diffusion flame (Amin and Roberts, 2017). However, the pressure scaling in ethylene counterflow flames depends on the mole fraction of fuel and oxidizer streams (Xue et al., 2018). Local soot concentration profiles agree with path averaged soot volume fraction profiles and peak values of $f_{\mathrm{v}, \text { local }}$ scale as $P^{3.9}$.

Increase in pressure results in an increase in coalescence due to which mean primary particle diameter increases while the number densities of primary particles decrease at each axial 
location as the pressure increases from 2 to $5 \mathrm{~atm} . \overline{d_{p}}$ increases with pressure up to 4 atm and changing pressure from 4 to $5 \mathrm{~atm}$, does not change $\overline{d_{p}}$ significantly. These trends are consistent with the ones obtained from ethylene flames (Gigone et al., 2019, Steinmetz et al., 2016) but contradicts with the pressurized flames of methane (Vargas and Gülder, 2016).

Mean aggregate size also increases from 3 to 5 atm due to increase in primary particle size. Increase in aggregate size might be accompanied by an increase in number of primary particles in an aggregate. The present investigations report quantitative dataset about soot parameters at elevated pressures which improves our understanding of the influence of pressure on soot.

\section{Acknowledgements}

The publication is based upon the work supported by King Abdullah University of Science and Technology (KAUST). A subset of this work was presented at CSP'16 and can be found at www.international-aset.com.

\section{References}

Amin, H. M. F., Bennett, A. \& Roberts, W. L. 2019. Determining fractal properties of soot aggregates and primary particle size distribution in counterflow flames up to $10 \mathrm{~atm}$. Proc. Combust. Inst., 37, 1161-1168.

Amin, H. M. F. \& Roberts, W. L. 2017. Soot measurements by two angle scattering and extinction in an N 2-diluted ethylene/air counterflow diffusion flame from 2 to 5atm. Proc. Combust. Inst., 36, 861-869.

Amin, H. M. F. \& Roberts, W. L. 2019. An experimental apparatus to measure soot morphology at high pressures using multi-angle light scattering. Meas. Sci. and Technol., 30, 075902. 
Bennett, A., Amin, H. M. F., Cenker, E. \& Roberts, W. L. 2018. Measurements of pressure effects on PAH distribution and 2D soot volume fraction diagnostics in a laminar non-premixed coflow flame. Energy Fuels, 32, 10974-10983.

Bo Yang \& U. O. Koylu 2005. Detailed soot field in a turbulent non-premixed ethylene/air flame from laser scattering and extinction experiments. Combust. Flame, 141, 55-65.

Broday, D. M. \& Rosenzweig, R. 2011. Deposition of fractal-like soot aggregates in the human respiratory tract. J. Aerosol Sci, 42, 372-386.

C. J. Sung, Li, B., H. Wang \& Law, C. K. 1998. Structure and sooting limits in counterflow methane/air and propane/air diffusion flames from 1 to 5 atmospheres. Proc. Combust. Inst. 27, 1523-1529.

CortéS, D., Morán, J., Liu, F., Escudero, F., Consalvi, J.-L. \& Fuentes, A. 2018. Effect of fuels and oxygen indices on the morphology of soot generated in laminar coflow diffusion flames. Energy Fuels, 32, 11802-11813.

Dasch, C. J. 1992. One-dimensional tomography: a comparison of Abel, onion-peeling, and filtered backprojection methods. Appl. Opt., 31, 1146-1152.

De Iuliis, S., Cignoli, F., Benecchi, S. \& Zizak, G. 1998a. Determination of soot parameters by a two-angle scattering-extinction technique in an ethylene diffusion flame. Appl. Opt., 37, 7865-7874.

De Iuliis, S., Cignoli, F., Benecchi, S. \& Zizak, G. 1998b. Investigation of the similarity of soot parameters in ethylene diffusion flames with different heights by extinction/scattering technique. Proc. Combust. Inst., 27, 1549-1555.

De Iuliis, S., Maffi, S., Cignoli, F. \& Zizak, G. 2011. Three-angle scattering/extinction versus TEM measurements on soot in premixed ethylene/air flame. Appl. Phys. B, 102, 891-903. 
Fang, T. C., Megaridis, C. M., Sowa, W. A. \& Samuelsen, G. S. 1998. Soot morphology in a liquid-fueled, swirl-stabilized combustor. Combust. Flame, 112, 312-328.

Ferraro, G., Fratini, E., Rausa, R., Fiaschi, P. \& Baglioni, P. 2016. Multiscale characterization of some commercial carbon blacks and diesel engine soot. Energy Fuels, 30, 9859-9866.

Figura, L., Carbone, F. \& Gomez, A. 2015. Challenges and artifacts of probing high-pressure counterflow laminar diffusion flames. Proc. Combust. Inst., 35, 1871-1878.

Figura, L. \& Gomez, A. 2014. Structure of incipiently sooting ethylene-nitrogen counterflow diffusion flames at high pressures. Combust. Flame, 161, 1587-1603.

Gigone, B., Karataş, A. E. \& Gülder, Ö. L. 2019. Soot aggregate morphology in coflow laminar ethylene diffusion flames at elevated pressures. Proc. Combust. Inst., 37, 841-848.

Hofmann, M., Bessler, W. G., Schulz, C. \& Jander, H. 2003. Laser-induced incandescence for soot diagnostics at high pressures. Appl. Opt., 42, 2052-2062.

Hu, B., Yang, B. \& Koylu, U. O. 2003. Soot measurements at the axis of an ethylene/air nonpremixed turbulent jet flame. Combust. Flame, 134, 93-106.

Joo, H. I. \& Gülder, Ö. L. 2010. Soot formation and temperature structure in small methaneoxygen diffusion flames at subcritical and supercritical pressures. Combust. Flame, 157, 1194-1201.

Joo, P. H., Gigone, B., Griffin, E. A., Christensen, M. \& Gülder, Ö. L. 2018. Soot primary particle size dependence on combustion pressure in laminar ethylene diffusion flames. Fuel, 220, 464-470.

Kennedy, I. M. 2007. The health effects of combustion-generated aerosols. Proc. Combust. Inst., 31, 2757-2770. 
Koylu, U. O. 1997. Quantitative analysis of in situ optical diagnostics for inferring particle/aggregate parameters in flames: Implications for soot surface growth and total emissivity. Combust. Flame, 109, 488-500.

Koylu, U. O., Xing, Y. \& Rosner, D. E. 1995. Fractal morphology analysis of combustiongenerated aggregates using angular light scattering and electron microscope images. Langmuir, 11, 4848-4854.

Krishnan, S. S., Lin, K.-C. \& Faeth, G. M. 2000. Optical properties in the visible of overfire soot in large buoyant turbulent diffusion flames. J. Heat Transfer, 122, 517-524.

Mandatori, P. M. \& Gülder, Ö. L. 2011. Soot formation in laminar ethane diffusion flames at pressures from 0.2 to $3.3 \mathrm{MPa}$. Proc. Combust. Inst., 33, 577-584.

Mei, J., Wang, M., Hou, D., Tang, Q. \& You, X. 2018. Comparative study on nascent soot formation characteristics in laminar premixed acetylene, ethylene, and ethane Flames. Energy Fuels, 32, 11683-11693.

Migliorini, F., Thomson, K. A. \& Smallwood, G. J. 2011. Investigation of optical properties of aging soot. Appl. Phys. B, 104, 273-283.

Pope Iii, C. A. \& Dockery, D. W. 2006. Health effects of fine particulate air pollution: lines that connect. J. Air Waste Manage. Assoc., 56, 709-742.

Ramanathan, V. \& Carmichael, G. 2008. Global and regional climate changes due to black carbon. Nature geoscience, 1, 221.

Sorensen, C. M. 2001. Light Scattering by Fractal Aggregates: A Review. Aerosol Sci. Technol., 35, 648-687. 
Sorensen, C. M., Cai, J. \& Lu, N. 1992. Light-scattering measurements of monomer size, monomers per aggregate, and fractal dimension for soot aggregates in flames. Appl. Opt., 31, 6547-6557.

Steinmetz, S. A., Fang, T. \& Roberts, W. L. 2016. Soot particle size measurements in ethylene diffusion flames at elevated pressures. Combust. Flame, 169, 85 - 93.

Thomson, K. A., Gulder, O. L., Weckman, E. J., Fraser, R. A., Smallwood, G. J. \& Snelling, D. R. 2005. Soot concentration and temperature measurements in co-annular, nonpremixed CH/air laminar flames at pressures up to 4 MPa. Combust. Flame, 140, 222-232.

Thomson, K. A., Johnson, M. R., Snelling, D. R. \& Smallwood, G. J. 2008. Diffuse-light twodimensional line-of-sight attenuation for soot concentration measurements. Appl. Opt., 47, 694-703.

Thomson, K. A., Snelling, D. R., Smallwood, G. J. \& Liu, F. 2006. Laser induced incandescence measurements of soot volume fraction and effective particle size in a laminar co-annular non-premixed methane/air flame at pressures between 0.5-4.0 MPa. Appl. Phys. B, 83, 469-475.

Vargas, A. M. \& Gülder, Ö. L. 2016. Pressure dependence of primary soot particle size determined using thermophoretic sampling in laminar methane-air diffusion flames. Proc. Combust. Inst., 36, 975-984.

Wang, Y. \& Chung, S. H. 2019. Soot formation in laminar counterflow flames. Progress in Energy and Combustion Science, 74, 152-238.

Xue, X., Singh, P. \& Sung, C.-J. 2018. Soot formation in counterflow non-premixed ethylene flames at elevated pressures. Combust. Flame, 195, 253-266. 
Yang, B. \& Koylu, U. O. 2005. Soot processes in a strongly radiating turbulent flame from laser scattering/extinction experiments. J. Quant. Spectrosc. Radiat. Transfer, 93, 289-299. 